\title{
Endoscopic Resection of Tuberculum Sellae Meningiomas
}

\author{
Nisha Gadgil ${ }^{1}$ Jonathan G. Thomas ${ }^{1}$ Masayoshi Takashima ${ }^{2}$ Daniel Yoshor ${ }^{1}$ \\ ${ }^{1}$ Department of Neurosurgery, Baylor College of Medicine, Houston, \\ Texas, USA \\ 2 Department of Otolaryngology, Baylor College of Medicine, Houston, \\ Address for correspondence Daniel Yoshor, MD, Department of \\ Neurosurgery, Baylor College of Medicine, 1709 Dryden, Suite 750,
} Texas, USA

J Neurol Surg B 2013;74:201-210.

\begin{abstract}
Keywords

- tuberculum sellae

- meningioma

- endoscopic approach

- transcranial

Objective To evaluate the results of endoscopic transnasal resection of tuberculum sellae meningiomas (TSMs) as compared with transcranial approaches.

Design We retrospectively analyzed five patients who underwent endoscopic endonasal resection of TSM and performed a comprehensive review of articles published between 2000 and 2012 describing the operative treatment of TSMs.

Results Gross total resection (GTR) was achieved in four patients (80\%). Transient diabetes insipidus occurred in three patients $(60 \%)$. Preoperative visual field deficit resolved in all patients. Cerebrospinal fluid (CSF) leak occurred in one patient. Analysis of published studies included 1,026 transcranial and 144 transnasal cases. GTR was achieved in $85 \%$ of transcranial and $72 \%$ of transnasal cases. Visual field deficit improved in $65 \%$ of transcranial and $82 \%$ of transnasal cases. Rate of diabetes insipidus and CSF leak was higher in the transnasal series. Rate of GTR and visual improvement was higher in endoscopic endonasal as compared with microsurgical transnasal series.

Conclusion The literature supports transsphenoidal surgery for the resection of TSMs with significant optic nerve compromise and limited lateral extension. This approach may have an equivalent if not superior outcome over transcranial surgery in visual outcome. CSF leaks are still a challenge but may improve with the use of vascularized nasoseptal flaps.
\end{abstract}

\section{Introduction}

Tuberculum sellae meningiomas (TSMs) represent 5 to $10 \%$ of all intracranial meningiomas. ${ }^{1-4}$ Originating from the tuberculum sellae or chiasmatic sulcus of the sphenoid bone, these suprasellar lesions often displace the optic chiasm and optic nerves, eventually causing visual impairment that is commonly the presenting symptom. . $^{2,3}$ TSMs have traditionally been removed transcranially via several different approaches, including bilateral subfrontal, ${ }^{3,5,6}$ unilateral subfrontal, ${ }^{7-9}$ pterional, ${ }^{4,10-16}$ and-more recently-lateral supraorbital ${ }^{17}$ and supraorbital keyhole craniotomies. ${ }^{18-20}$
There is a growing acceptance that endoscopic transnasal surgery is a useful alternative to transcranial approaches in surgery for anterior skull base lesions such as pituitary adenomas, craniopharyngiomas, chordomas, and meningiomas. Among this group of tumors, TSMs may be particularly well suited for resection through this operative corridor, as they require a longer reach and potentially more brain retraction when removed transcranially. Other potential advantages of the transnasal approach include early decompression of optic structures, avoidance of damage to subchiasmatic perforating vessels, and early devascularization. 2,21-24 Despite these theoretical advantages, the received

September 4, 2012

accepted after revision

January 22, 2013

published online

April 12, 2013 (c) 2013 Georg Thieme Verlag KG Stuttgart · New York
DOI http://dx.doi.org/ 10.1055/s-0033-1342922. ISSN 2193-6331. 
application of endoscopic endonasal surgery in the treatment TSMs has been reported in only a limited number of series. ${ }^{3,23-29}$ Moreover, questions have persisted about shortcomings of the endoscopic approach, including limitations in the ability to perform precise bimanual microdissection, lack of stereoscopic vision, and the high risk of cerebrospinal fluid (CSF) leak. ${ }^{25,28,30}$ For these reasons, transnasal resection of TSMs merits further scrutiny and careful comparison to the traditional transcranial approach with respect to clinical outcomes. We describe our recent experience with five cases of TSMs treated with endoscopic endonasal surgery and review the recent literature on transnasal and transcranial approaches.

\section{Methods}

\section{Study Design and Patient Population}

Between September 2009 and September 2011, five patients with TSMs underwent extended endoscopic endonasal transsphenoidal surgery performed by the senior author (DY) in conjunction with an otolaryngologist (MT) at St. Luke's Episcopal Hospital, Houston, TX. Demographic data, medical histories, surgical procedure, visual and endocrinological outcomes, and complications were retrospectively analyzed. The follow-up period was 3 to 27 months (mean of 15 months). This study was approved by the Baylor College of Medicine Institutional Review Board.

\section{Surgical Technique}

In four of the five patients, a lumbar drain was placed prior to beginning the surgery. The patient's head was fixed in a Mayfield headholder and a fused computed tomography (CT)/magnetic resonance imaging (MRI) image-guidance device was attached and registered. The nares were then inspected, and septoplasty was performed if septal deviation was found to obstruct the passage of endonasal instruments.
In all but one case (a reoperation in a patient who had previously undergone a transseptal approach at another center), a nasoseptal flap based off septal branches of the sphenopalatine artery was harvested to the level of the columella. If needed, a posterior ethmoidectomy was performed to permit access to the face of the sphenoid. Subsequently, a generous sphenoidotomy and posterior septectomy was performed for wide visualization of the skull base, including planum, tuberculum sella, and sella. Image guidance was used to confirm anatomic landmarks, including optic canals, carotid protuberances, and lateral and medial opticocarotid recesses. The sella and the tuberculum between the medial opticocarotid recesses were drilled with a diamond bur with generous irrigation until thin enough to be safely flicked off. The dura overlying the tuberculum and planum was opened sharply, using the endoscopic bipolar and hemostatic agents to control any dural or intercavernous bleeding. After internally debulking the tumor with a suction or a side-cutting aspiration device, bimanual dissection was employed to dissect the tumor from the optic nerves and floor of the third ventricle, maintaining the arachnoidal plane. The angled endoscope was used to circumferentially inspect for any residual. Once resection was deemed complete, or if further resection would endanger critical structures, a dural substitute inlay graft was placed inside the dural defect and the nasoseptal flap was then laid over the bony opening and held in place with fibrin glue. Finally, nasal tampons were placed to help buttress the reconstruction.

\section{Assessment}

All patients presenting with visual symptoms underwent preoperative and postoperative visual testing by an ophthalmologist, including formal visual field testing. Comprehensive endocrinological testing of anterior and posterior pituitary function was performed where appropriate. Preop-

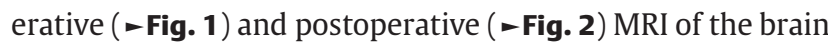

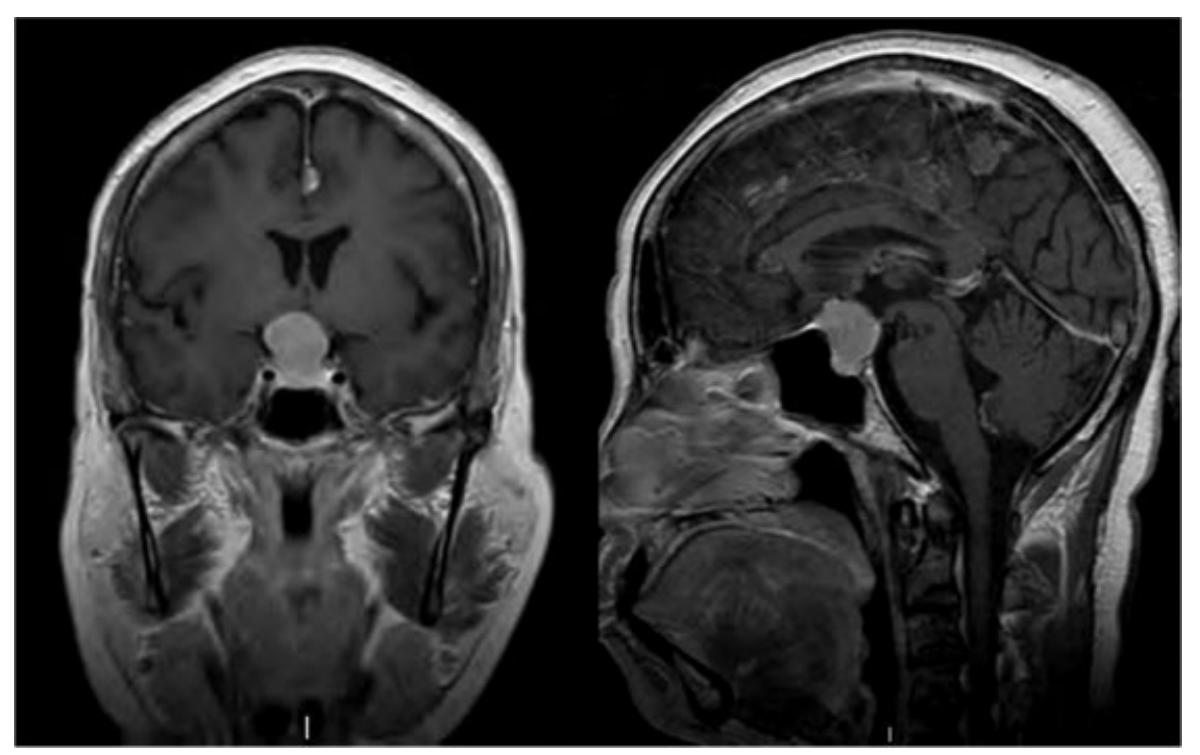

Fig. 1 Preoperative coronal and sagittal magnetic resonance imaging with contrast showing a tuberculum sellae meningioma compressing the optic chiasm. 


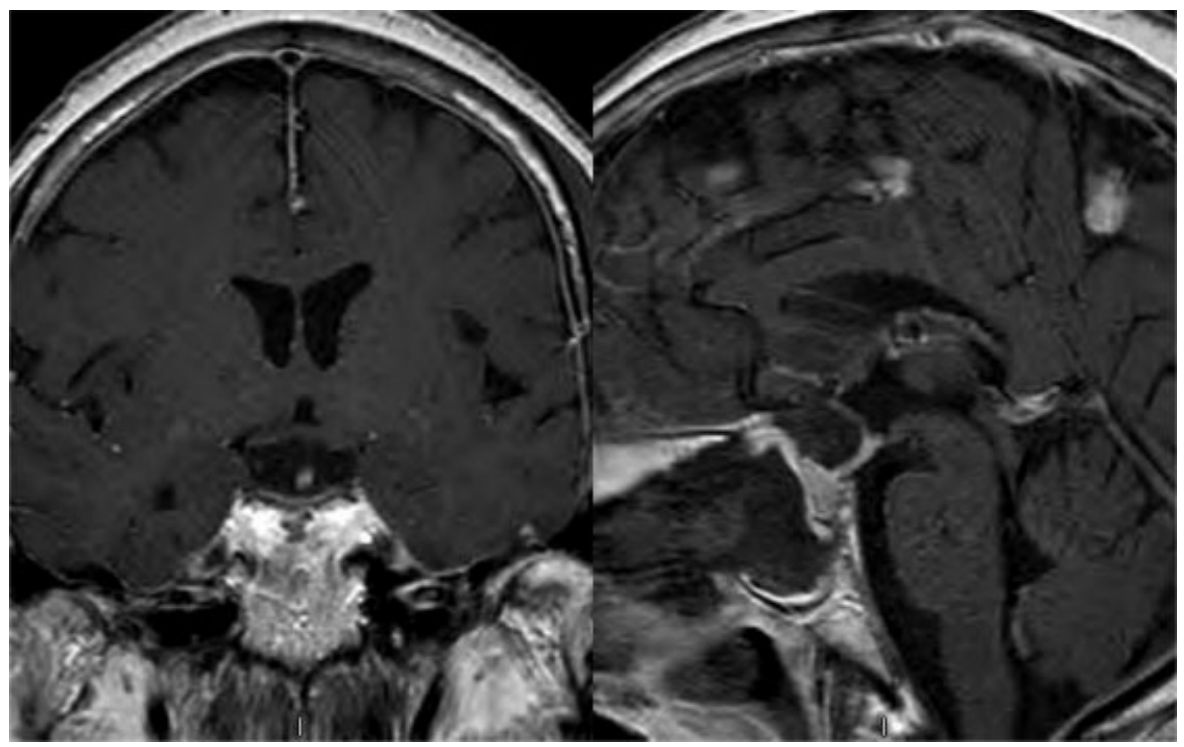

Fig. 2 Postoperative coronal and sagittal magnetic resonance imaging with contrast showing no evidence of residual tumor. Note the avidly enhancing nasoseptal flap.

with and without administration of gadolinium was performed for all patients. The extent of tumor resection was assessed by the senior author at the time of surgery and confirmed by postoperative imaging.

\section{Literature Search}

A search of the PubMed database was performed to identify all articles published between January 1, 2000, and January 31, 2012, that discussed operative treatment of TSMs. Meningioma, tuberculum sellae, endoscopy, transsphenoidal, and transcranial were used as search terms. We limited our search to literature after January 1, 2000, to allow for better comparison between transcranial and transsphenoidal series. We then searched all references in these manuscripts. Only articles in English were reviewed. Articles were included that clearly reported the treatment modality used. Reports including other types of anterior skull base meningiomas (e.g., planum sphenoidale or olfactory groove) that were inseparable in the results were excluded. When a single center had provided more than one report of its results, the longest follow-up was used for the analysis of outcomes. Data from individual reports and case series were extracted. In series using more than one operative approach in which disaggregated data was not provided, data was collected under the heading "mixed series." We attempted to report visual outcome data only for those patients who were known to have a visual deficit preoperatively. Gross total resection (GTR), visual outcome, and complications are reported as a percentage of patients for which this data was provided, which may not be equal to the total number of patients in the series reviewed. Due to the heterogeneity of data reported and paucity of disaggregated data, no statistical analysis was performed. This data was designed to be descriptive rather than absolute.

\section{Results}

\section{Demographic Data and Clinical Presentations}

The cohort included 3 women and 2 men, ages ranging from 31 to 66 years (mean, 51 years). The most common presenting symptom was visual loss. In one patient who had previously undergone transseptal transsphenoidal microsurgery for a coexisting pituitary adenoma years before, the lesion was found on routine follow-up imaging (No. 3). One patient had previously undergone radiation at the age of 6 years for tinea capitis (No. 4) and was noted to have multiple intracranial lesions in addition to a TSM. A summary of the characteristics and outcomes of all patients is provided in -Table 1.

\section{Imaging Evaluation Results}

Tumor size, as estimated by the maximal linear dimensions on preoperative MRI, varied from $2.3 \mathrm{~cm}^{3}$ to $11.9 \mathrm{~cm}^{3}$ (mean, $6.3 \mathrm{~cm}^{3}$ ). Lateral extension of the tumor ranged from $0.9 \mathrm{~cm}$ to $2.5 \mathrm{~cm}$ (mean, $1.9 \mathrm{~cm}$ ). Optic chiasm and/or optic nerve compression was noted in all cases. Cavernous extension of the TSM was noted in one patient (No. 4). Lateral optic canal extension was not noted in any of the patients.

\section{Operative Findings}

Estimated blood loss was 200 to $300 \mathrm{~mL}$ (mean, $220 \mathrm{~mL}$ ). The optic nerves and chiasm were visualized and fully decompressed in all patients. In all patients, the skull base was repaired with an inlay of dural substitute and a nasoseptal flap onlay reinforced with fibrin glue. Fat harvested from the abdomen was used to reinforce the sella repair in two patients (No. 2 and No. 4). Histopathology confirmed grade I meningioma in all cases. 


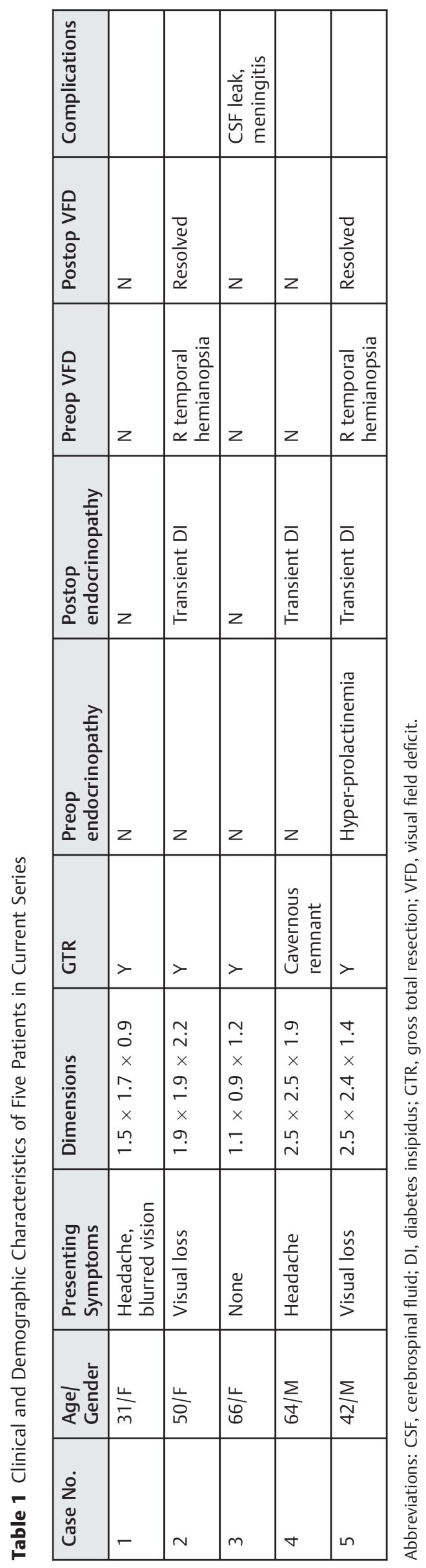

\section{Evaluation of Tumor Removal}

Simpson Grade I tumor resection was achieved in four of the five patients (80\%). Subtotal resection was performed in the patient noted to have significant intracavernous extension of the lesion (No. 4). Postoperative MRI imaging confirmed residual tumor only in this patient.

\section{Endocrine Results}

No patients were found to have preoperative diabetes insipidus (DI). DI developed transiently in the postoperative period in 3 patients, resolving within 2 to 3 days of surgery in 2 of these patients and within 3 weeks of surgery in the third patient.

\section{Ophthalmological Results}

Two patients had a preoperative hemianopsia, verified by formal visual field testing. Postoperatively, in both cases, visual acuity and visual fields normalized after surgery. Subjective improvement of vision was reported by two other patients with visual complaints and no visual field deficit. Follow-up did not reveal new visual deterioration in any of the patients.

\section{Postoperative Care}

A lumbar drain was placed at the time of operation in 4 of the 5 patients and removed on postoperative day 1 in one patient (No. 4), postoperative day 2 in one patient (No. 5), and postoperative day 4 in two patients (No. 1, No. 2). The timing of lumbar drain removal was individualized and usually reflected the size of the skull base defect. Recently, we have attempted to remove lumbar drains early postoperatively or avoid them entirely. Patients were discharged with nasal packing in place, which was removed in follow-up clinic between postoperative days 5 and 9 . Duration of hospital stay varied from 1 to 6 days (mean, 3 days).

\section{Complications}

No perioperative mortality or permanent neurological deficit occurred in any patient in this study. In the patient (No. 3) who had previously undergone transsphenoidal surgery and septoplasty for a pituitary adenoma, we were unable to harvest a viable nasoseptal flap for the reconstruction. This patient presented on postoperative day 14 with CSF rhinorrhea. Though she did not have meningeal signs, CSF sampling revealed a meningitis for which she was treated with the appropriate antibiotics. She was taken back to the operating room, and the previous inlay graft was buttressed with an abdominal fat graft. The patient recovered uneventfully and was doing well at last follow-up.

Tumor recurrence was not noted in any of the patients on postoperative imaging during the follow-up period of 12 to 36 months (mean, 24 months).

\section{Review of Literature}

Transcranial Surgery

Our literature search revealed 1,026 TSMs in 32 published series resected using transcranial surgery since 2000 
(-Table 2). ${ }^{1-20,31-42}$ The surgical approach was pterional in 541 (52.7\%), unilateral subfrontal in 129 (12.6\%), bilateral subfrontal in 81 (7.9\%), supraorbital in 123 (12.0\%), interhemispheric in 41 (4.0\%), and other or not specified in 111 (10.8\%). Overall, $85 \%$ of surgeries achieved GTR, defined as Simpson Grade I or II, out of the 993 for which this data was reported. The pterional approach had a GTR of $87 \%$ out of 333 reported, unilateral subfrontal $83.0 \%$ out of 23 reported, bilateral subfrontal $90 \%$ out of 29 reported, supraorbital $76.6 \%$ out of 77 reported, and interhemispheric $91 \%$ out of 33 reported; the mixed transcranial series had a GTR of $85 \%$ out of 498 cases. Vision was improved after surgery in 65\% out of 858 transcranial cases for which this data was reported. The pterional approach showed improvement of vision in $68 \%$ of 266 cases reported, unilateral subfrontal $73 \%$ of 23 reported, bilateral subfrontal $50 \%$ of 42 reported, supraorbital $52.9 \%$ of 51 reported, interhemispheric $82 \%$ of 33 reported, and mixed series $63 \%$ of 451 cases reported. Worsening of vision was seen in $14 \%$ of 895 patients overall. DI was noted postoperatively in a total of 45 cases (4.8\% of 943 reported), which was considered permanent in 3 cases (0.3\%). Six cases of transient DI were noted in 310 cases using the pterional approach (1.9\%).

Complications of each surgical procedure are noted in - Table 2. Death occurred in 11 of 930 cases for which complications were reported (1.2\%). Other reported complications besides DI and death (such as neurologic deficit, infection, CSF leak, and anosmia) occurred in 190 cases (20\%). CSF leak occurred in $3.8 \%$ of patients and anosmia or hyposmia occurred in 5.1\%. Recurrence occurred in 36 of 915 cases (3.9\%); however, follow-up time varied widely.

\section{Transnasal Surgery}

Our literature search revealed a total of 144 TSMs in 16 series, including our own, resected with a transnasal approach reported since $2000,2,3,21-29,31,34,43$ including 77 employing the microscope (53.5\%) and 67 the endoscope (46.5\%) (- Table 3). GTR was achieved in $72 \%$ of 119 cases overall for which this data was reported, 65\% microsurgical and 78\% endoscopic approaches. In the 95 cases that reported postoperative visual outcome, vision was noted to improve in $82 \%$, with $76 \%$ of microsurgical and $87 \%$ of endoscopic cases. Worsening of vision was seen in $8 \%$ of 88 cases overall, $19 \%$ of microsurgical and $0 \%$ of endoscopic cases. DI occurred in 8 out of 73 patients for which this complication was reported (11\%), $4.7 \%$ of microsurgical and $20 \%$ of endoscopic cases. DI was permanent in two cases, both endoscopic, and was transient in all other cases. Death resulting from intraventricular hemorrhage was noted in one case of TSM treated endoscopically. No other death was reported. Complications other than DI were reported in $37 \%$ of total cases. CSF leak occurred in 28 of cases out of 133 cases overall (21\%), 14 in microsurgical cases (18\%) and 14 in endoscopic cases (26\%). Recurrence of tumor was not reported in the majority of series.

\section{Discussion}

TSMs are slow-growing dural-based tumors that are rarely malignant, but their location at the skull base and close relationship to important neural, vascular, and endocrinologic structures render surgical treatment challenging. As they grow, TSMs typically displace the optic nerves and internal carotids laterally, and the chiasm posteriorly. They usually maintain an extra-arachnoidal location, creating a plane between the tumor and surrounding structures but exerting a compressive effect. Although they typically do not invade vessels, they may adhere to vessel walls or even engulf them. Visual dysfunction is the most common presenting complaint. $^{44}$

There are several key structures to consider in the surgical approach to TSMs. Preservation of visual function and minimization of trauma to the optic apparatus are of utmost importance. Cognizance of nearby vascular structures such as the internal carotid and anterior cerebral arteries that may be displaced is also essential. Special consideration for transnasal approaches is paid to the minimization of postoperative CSF leaks. Permanent or transient DI and endocrine insufficiency may result from damage to the pituitary stalk or gland. True radical resection of the affected dura and involved bone is curative of TSMs; however, most surgeons agree that regardless of the chosen approach, complete removal should not be performed if attendant risk to critical neurovascular structures is deemed too high. In these cases, a small remnant may be left with continued close follow-up thereafter, as was done in patient No. 4 of our series.

The optimal surgical technique for the removal of TSMs is a subject of wide debate. Transcranial surgery, which can be performed via several different approaches, has traditionally been the treatment of choice for suprasellar lesions. However, advances in transsphenoidal surgery have challenged the primacy of transcranial surgery in the treatment of suitable suprasellar lesions such as craniopharyngiomas and TSMs. To compare the outcomes of transcranial versus transsphenoidal surgery, we performed a comprehensive review of the recent literature after the year 2000 on the surgical treatment of TSMs. We discuss the results of this review and outline the pros and cons of each surgical approach.

\section{Transcranial Surgery}

The most commonly used approaches in transcranial surgery for TSMs are bilateral subfrontal, unilateral subfrontal, pterional, and more recently supra-orbital keyhole. In our review of the literature, we did not feel that there was adequate disaggregated data to compare the outcomes of the various approaches; thus we will discuss the theoretical advantages of each.

The subfrontal approach, once more widely used, has waned in popularity: out of 1,026 cases reviewed, only $12.6 \%$ were performed by unilateral subfrontal approach and $7.9 \%$ by bilateral subfrontal. Although the bilateral approach gives a wide and direct view of both optic nerves with minimal manipulation of the optic apparatus, ${ }^{33,45}$ the main disadvantage is that it requires elevation of both frontal lobes. A high incidence of postoperative brain edema and venous brain infarction has been noted, and the neuropsychological effects of frontal lobe retraction are receiving greater attention, leading some to disfavor the technique. ${ }^{36}$ Potential 


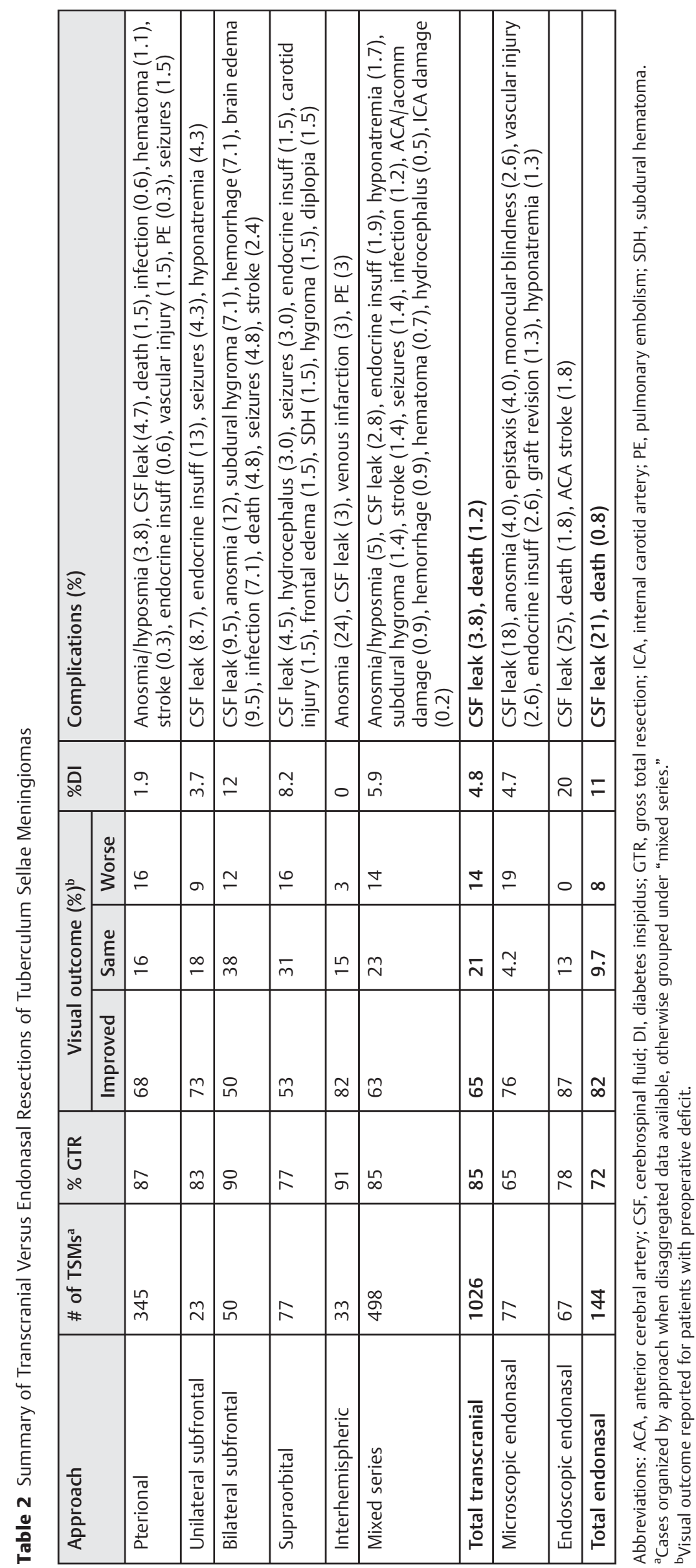




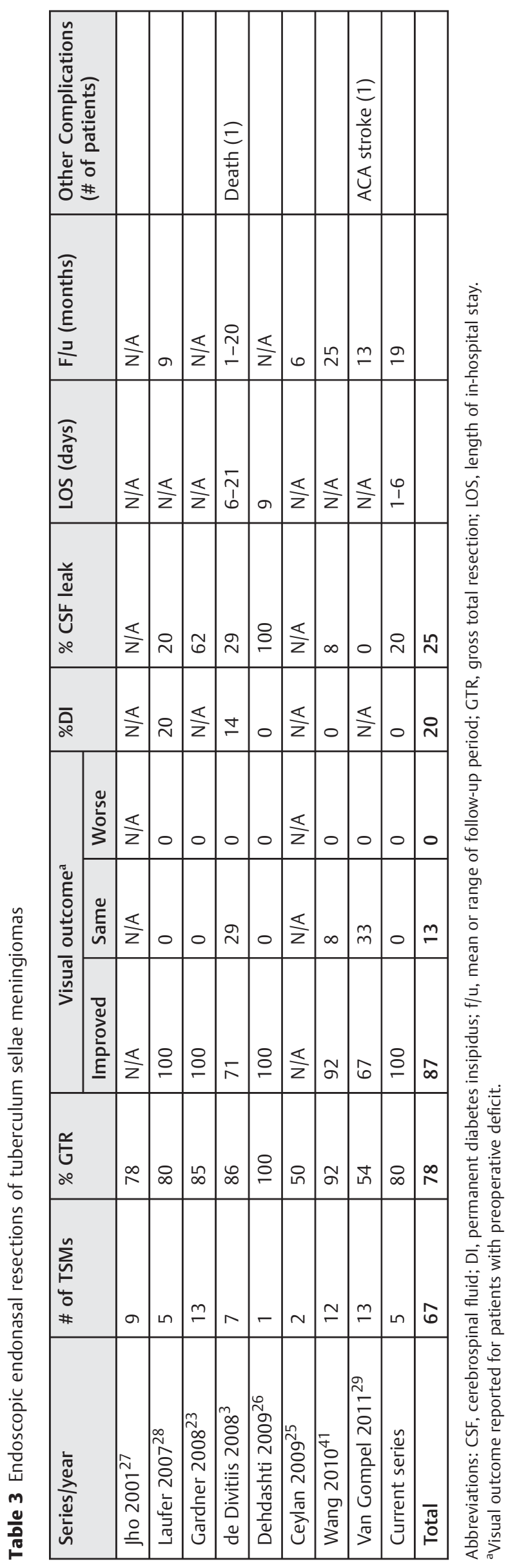

injury to the anterior cerebral artery (ACA) is another cause of significant morbidity. ${ }^{1}$ The olfactory tracts must be dissected and may also incur damage during the procedure. Finally, the technique often involves opening of the frontal sinus, risking CSF leak and meningitis. ${ }^{36}$ Although the unilateral subfrontal approach obviates the need for bilateral retraction, it results in a more limited view of the optic apparatus, ${ }^{45}$ and therefore the bifrontal approach is often preferred for large tumors. ${ }^{33}$

Out of the cases reviewed, the pterional approach was the most popular (52.7\%). This technique represents a shorter distance to the tuberculum sellae and does not require frontal sinus opening. ${ }^{33,45}$ The procedure allows for early removal of CSF from the basal cisterns to allow brain relaxation, early identification of the optic nerve and carotid before tumor dissection, and preservation of the contralateral olfactory nerve. ${ }^{33}$ However, frontal brain retraction may still be required, and the operative corridor can require manipulation of the ipsilateral optic nerve and carotid, which are between the operator and the tumor. ${ }^{33,35}$

Recently, there has been interest in the use of the supraorbital approach as a less-invasive alternative to typical transcranial methods, either through a supraorbital keyhole $18,19,31,38$ or as modification of the pterional approach. ${ }^{17}$ The supraorbital keyhole employs microsurgery and/or endoscopy to reduce the size of the craniotomy and reduce postoperative discomfort. ${ }^{18}$ Exposure is limited, but the use of the endoscope broadens the surgical view. Complications include damage to the frontotemporal branch of the facial nerve and occult frontal sinusotomy, ${ }^{18,38}$ as well as cosmetic concerns. The lateral supraorbital approach is a less-invasive modification of the pterional approach that may reduce the incidence of postoperative brain edema and venous infarction. This approach has similar surgical results as more extensive transcranial approaches. ${ }^{17}$

\section{Transnasal versus Transcranial Surgery}

To obtain direct access to midline anterior skull base lesions without encountering interceding brain or neurovascular structures, transnasal approaches are increasingly being utilized. Originally used for primarily sellar lesions, this approach has been modified to access suprasellar lesions as well, known as the extended transsphenoidal approach. ${ }^{22}$ This modification requires additional removal of bone along the tuberculum sellae and posterior planum sphenoidale and opening of the dura to allow access to the suprasellar space.

Among anterior skull base meningiomas, TSMs are particularly well suited to transnasal resection. Due to their proximity to the optic apparatus and pituitary gland, these tumors typically present with a relatively small size that facilitates easier resection through the transnasal corridor. The transnasal approach allows a direct and natural angle of approach to the base of these tumors. In comparison, meningiomas arising from the planum or olfactory groove are typically larger in size and require a more vertically angulated view.

Comparison between transcranial and transnasal approaches is limited due to the heterogeneity of cases and selection biases. Transnasal series are significantly skewed toward smaller lesions ${ }^{29}$ and more midline tumors. 
Nevertheless, it is useful to compare the relative advantages and disadvantages of the two approaches.

Visual outcome is one of the most important factors to consider in the surgical treatment of TSMs. ${ }^{13,24,39}$ In our review of literature, postoperative improvement of vision was seen in $82 \%$ of cases using the transsphenoidal approach, which compares favorably to the $65 \%$ reported in the transcranial approach series. Worsening of vision was seen in $8 \%$ of cases in the transsphenoidal group, compared with $14 \%$ in the transcranial group. Though direct comparison of these disparate series is difficult, we believe the following factors contribute to these striking results.

First, the optic apparatus is often severely stretched by the TSM and therefore very sensitive to surgical manipulation. The transsphenoidal approach to the suprasellar space eliminates the need for manipulation of the already compressed optic apparatus. $^{22-24}$ Second, approaching the TSM from below allows the operator to stay within the arachnoid plane and protect the optic apparatus. Subchiasmatic perforators that provide the blood supply to the optic chiasm are therefore visualized early and damage to them avoided. ${ }^{24}$ Lastly, because TSMs typically displace the optic apparatus superiorly, the transsphenoidal approach allows that tumor may be removed beneath the chiasm immediately after entering the suprasellar space. Thus, decompression of optic structures occurs early. If tumor involves the lateral optic canal, there is little controversy that the transcranial approach is superior. However, for midline tumors, the transnasal approach may have a better visual outcome.

Postoperative CSF leak is a potential complication of both transnasal and transcranial approaches. However, it is certainly more common with the transnasal approach, which requires reconstruction of the skull base using careful grafting closure to prevent leak. ${ }^{21-23}$ In our review of literature, CSF leak was noted to occur in $21 \%$ of transsphenoidal cases, yet also in $3.8 \%$ of transcranial cases. The use of a vascularized flap pedicled on the nasoseptal artery has greatly enhanced the ability to reconstruct anterior skull base defects. ${ }^{23,46}$ This technique has resulted in a drop in CSF leak rate for endoscopic anterior fossa approaches. ${ }^{47}$ The only case of CSF leak in our series occurred in a patient in which we could not elevate a viable nasoseptal flap due to previous transsphenoidal surgery. In reconstructing the skull base defect, we prefer using a thin inlay graft of a dural substitute that closely apposes the dura and is not bulky and thus spares the optic apparatus from compression from the reconstruction. Continued development and refinement of flap coverage techniques will likely improve CSF leak rates after transnasal surgery, although this complication will likely be more common in transnasal as compared with transcranial approaches.

As with the transcranial approach, cognizance and preservation of the pituitary stalk and superior hypophyseal artery is paramount to preventing permanent DI or hypopituitarism. Using the transsphenoidal approach, permanent postoperative DI was noted in $2.7 \%$ of cases. In contrast, $0.3 \%$ of patients in the transcranial series experienced permanent DI. These results may reflect the possibility of damage to small hypothalamic perforating arteries or the pituitary stalk using the transnasal approach. Transient DI is a relatively more common postoperative complication, and diagnosis and treatment of this condition varies widely. Three of the five patients in our series experienced transient postoperative DI, though in two patients it resolved within a few days of surgery. In our experience, hospital admission is not usually prolonged by the presence of DI if extensive patient education has taken place.

Extent of resection is important in predicting risk of recurrent tumor and possible need for additional treatment. In our review of the literature, transcranial series proved to have a higher rate of GTR (85\% versus $72 \%$ in transnasal series). This is likely due to the wider exposure and visibility afforded by transcranial techniques. However, follow-up data are insufficient at this time to compare rate of tumor recurrence between the two approaches.

Several other factors related to surgical morbidity of transcranial versus transnasal approaches deserve mention. The transnasal approach obviates the need for brain retraction, greatly reducing the incidence of brain edema and venous infarction. The neuropsychological effects of frontal lobe retraction are also being increasingly recognized. Although not always reported as a complication, edema is a relatively common consequence of transcranial surgery. In addition, the transsphenoidal approach allows a relatively bloodless debulking of tumor. Feeding vessels to TSMs often arise from the ethmoidal arteries and dural base and may be coagulated prior to entering the tumor., ${ }^{2,21}$ This factor may contribute to the significant decrease in intraoperative blood loss seen in transsphenoidal versus transcranial surgery for TSMs. $^{34}$

Currently, the literature supports transsphenoidal surgery as an option for the resection of small to medium-sized midline TSMs with limited extension. Transcranial surgery may be more appropriate for large TSMs $(>3 \mathrm{~cm})$ with significant lateral extension, vascular encasement, or significant invasion into the optic canal. ${ }^{2,3,21,22,25,26,43}$ Typically, we use the lateral part of the optic canal as the anatomic lateral limit of transsphenoidal resection, as resection beyond that point requires manipulation of the optic apparatus, nullifying the major advantage of this approach. With improved technique and increasing experience, it remains to be seen whether endoscopic endonasal surgery will allow the safe removal of larger, more extensive TSMs.

\section{Microsurgical vs Endoscopic Transsphenoidal Surgery}

Transsphenoidal surgery for TSMs may be accomplished using 3 methods: microsurgery, endoscopic assisted microsurgery, and purely endoscopic surgery. Microsurgery is conventionally performed transseptally using a sublabial or endonasal approach. However, the extent of exposure provided by the narrow view of the operating microscope is limiting, especially in TSMs with lateral extension. ${ }^{21,24}$

The angled endoscope provides superior visualization of the suprasellar space and close-up, unobstructed views of the microanatomy. ${ }^{2,21,24,26,27}$ Purely endoscopic endonasal surgery takes advantage of the magnified, panoramic view provided by the endoscope. This operation is a two-surgeon 
procedure requiring coordination with a rhinologist. Endoscopy, in contrast to microsurgery, does not require the use of a transsphenoidal retractor, allowing increased flexibility of instrumentation and minimization of rhinological trauma. Greater flexibility in trajectory may allow for the removal of larger tumors involving the parasellar space. ${ }^{27,28}$ Loss of stereoscopic vision can be compensated for by dynamic adjustment of the endoscopic depth to help gauge distance.

Improvement in visibility and ease of instrumentation, and the ability to use angled scopes in the endoscopic endonasal approach, may contribute to a better visual outcome and rate of complete tumor resection. In our review, vision was noted to improve in $87 \%$ of endoscopic cases and vision worsened in none, versus $76 \%$ improvement in microsurgical cases and vision worsening in $19 \%$. The rate of GTR was also improved: $65 \%$ of microsurgical cases versus $78 \%$ of endoscopic cases.

\section{Limitations}

As pointed out by other series, there is a significant selection bias related to tumor size between transcranial and transsphenoidal series. ${ }^{29}$ The published studies concerning transsphenoidal surgery are few, and analysis is made difficult by heterogeneity in reporting data and inclusion of a variety of lesions, not just TSMs, in the studies. The lack of long-term follow-up limits outcome assessment. For this reason, our review of literature is a descriptive rather than statistical comparison between the two approaches. Despite these limitations, we believe that comparing the advantages and disadvantages of the two approaches is appropriate and useful.

\section{Conclusion}

A review of the literature and our own series of five cases confirms that for well-selected TSMs with significant optic nerve compromise and limited lateral extension, endoscopic endonasal resection is an excellent option. For suitably sized TSMs, this approach may have an equivalent if not superior outcome over transcranial surgery in visual outcome and rate of complete tumor resection. Postoperative CSF leaks are still a challenge-but though once considered technique-limiting, they are now manageable. However, most surgeons agree that transcranial surgery is still considered the treatment of choice for tumors of large size, invasion of the optic canal, and vascular encasement. ${ }^{22,26,31}$ As the published experience with endoscopic endonasal surgery increases and longterm data are obtained, its advantages for suprasellar lesions such as TSMs will likely be borne out.

\section{References}

1 Bassiouni H, Asgari S, Stolke D. Tuberculum sellae meningiomas: functional outcome in a consecutive series treated microsurgically. Surg Neurol 2006;66(1):37-44, discussion 44-45

2 Bowers CA, Altay T, Couldwell WT. Surgical decision-making strategies in tuberculum sellae meningioma resection. Neurosurg Focus 2011;30(5):E1
3 de Divitiis E, Esposito F, Cappabianca P, Cavallo LM, de Divitiis O. Tuberculum sellae meningiomas: high route or low route? A series of 51 consecutive cases. Neurosurgery 2008;62(3):556-563, discussion 556-563

4 Jallo GI, Benjamin V. Tuberculum sellae meningiomas: microsurgical anatomy and surgical technique. Neurosurgery 2002; 51(6):1432-1439, discussion 1439-1440

5 Arai H, Sato KOkuda, et al. Transcranial transsphenoidal approach for tuberculum sellae meningiomas. Acta Neurochir (Wien) 2000;142(7):751-756, discussion 756-757

6 Margalit NS, Lesser JB, Moche J, Sen C. Meningiomas involving the optic nerve: technical aspects and outcomes for a series of 50 patients. Neurosurgery 2003;53(3):523-532, discussion 532-533

7 Goel A, Muzumdar D, Desai KI. Tuberculum sellae meningioma: a report on management on the basis of a surgical experience with 70 patients. Neurosurgery 2002;51(6):1358-1363, discussion 1363-1364

8 Kim TW, Jung S, Jung TY, Kim IY, Kang SS, Kim SH. Prognostic factors of postoperative visual outcomes in tuberculum sellae meningioma. Br J Neurosurg 2008;22(2):231-234

9 Landeiro JA, Gonçalves MB, Guimarães RD, et al. Tuberculum sellae meningiomas: surgical considerations. Arq Neuropsiquiatr 2010; 68(3):424-429

10 Ciric I, Rosenblatt S. Suprasellar meningiomas. Neurosurgery 2001;49(6):1372-1377

11 Fahlbusch R, Schott W. Pterional surgery of meningiomas of the tuberculum sellae and planum sphenoidale: surgical results with special consideration of ophthalmological and endocrinological outcomes. J Neurosurg 2002;96(2):235-243

12 Mathiesen T, Kihlström L. Visual outcome of tuberculum sellae meningiomas after extradural optic nerve decompression. Neurosurgery 2006;59(3):570-576, discussion 570-576

13 Otani N, Muroi C, Yano H, Khan N, Pangalu A, Yonekawa Y. Surgical management of tuberculum sellae meningioma: role of selective extradural anterior clinoidectomy. Br J Neurosurg 2006;20(3): 129-138

14 Pamir MN, Ozduman K, Belirgen M, Kilic T, Ozek MM. Outcome determinants of pterional surgery for tuberculum sellae meningiomas. Acta Neurochir (Wien) 2005;147(11):1121-1130, discussion 1130

15 Sade B, Lee JH. High incidence of optic canal involvement in tuberculum sellae meningiomas: rationale for aggressive skull base approach. Surg Neurol 2009;72(2):118-123, discussion 123

16 Schick U, Hassler W. Surgical management of tuberculum sellae meningiomas: involvement of the optic canal and visual outcome. J Neurol Neurosurg Psychiatry 2005;76(7):977-983

17 Romani R, Laakso A, Kangasniemi M, Niemelä M, Hernesniemi J. Lateral supraorbital approach applied to tuberculum sellae meningiomas: experience with 52 consecutive patients. Neurosurgery 2012;70(6):1504-1518, discussion 1518-1519

18 Fernandes YB, Maitrot D, Kehrli P, Tella OI Jr, Ramina R, Borges G. Supraorbital eyebrow approach to skull base lesions. Arq Neuropsiquiatr 2002;60(2-A):246-250

19 Kabil MS, Shahinian HK. Application of the supraorbital endoscopic approach to tumors of the anterior cranial base. J Craniofac Surg 2005;16(6):1070-1074, discussion 1075

20 Mahmoud M, Nader R, Al-Mefty O. Optic canal involvement in tuberculum sellae meningiomas: influence on approach, recurrence, and visual recovery. Neurosurgery 2010;67(3, Suppl Operative):ons108-ons118, discussion ons118-ons119

21 Couldwell WT, Weiss MH, Rabb C, Liu JK, Apfelbaum RI, Fukushima T. Variations on the standard transsphenoidal approach to the sellar region, with emphasis on the extended approaches and parasellar approaches: surgical experience in 105 cases. Neurosurgery 2004;55(3):539-547, discussion 547-550

22 Dusick JR, Esposito F, Kelly DF, et al. The extended direct endonasal transsphenoidal approach for nonadenomatous suprasellar tumors. J Neurosurg 2005;102(5):832-841 
23 Gardner PA, Kassam AB, Thomas A, et al. Endoscopic endonasal resection of anterior cranial base meningiomas. Neurosurgery 2008;63(1):36-52, discussion 52-54

24 Wang Q Lu XJ, Ji WY, et al. Visual outcome after extended endoscopic endonasal transsphenoidal surgery for tuberculum sellae meningiomas. World Neurosurg 2010;73(6):694-700

25 Ceylan S, Koc K, Anik I. Extended endoscopic approaches for midline skull-base lesions. Neurosurg Rev 2009;32(3):309-319, discussion 318-319

26 Dehdashti AR, Ganna A, Witterick I, Gentili F. Expanded endoscopic endonasal approach for anterior cranial base and suprasellar lesions: indications and limitations. Neurosurgery 2009;64(4): 677-687, discussion 687-689

27 Jho HD. Endoscopic transsphenoidal surgery. J Neurooncol 2001; 54(2):187-195

28 Laufer I, Anand VK, Schwartz TH. Endoscopic, endonasal extended transsphenoidal, transplanum transtuberculum approach for resection of suprasellar lesions. J Neurosurg 2007;106(3):400-406

29 Van Gompel JJ, Frank G, Pasquini E, Zoli M, Hoover J, Lanzino G. Expanded endonasal endoscopic resection of anterior fossa meningiomas: report of 13 cases and meta-analysis of the literature. Neurosurg Focus 2011;30(5):E15

30 Frank G, Pasquini E. Tuberculum sellae meningioma: the extended transsphenoidal approach-for the virtuoso only? World Neurosurg 2010;73(6):625-626

31 Fatemi N, Dusick JR, de Paiva Neto MA, Malkasian D, Kelly DF. Endonasal versus supraorbital keyhole removal of craniopharyngiomas and tuberculum sellae meningiomas. Neurosurgery 2009; 64(5, Suppl 2):269-284, discussion 284-286

32 Galal A, Faisal A, Al-Werdany M, El Shehaby A, Lotfy T, Moharram $\mathrm{H}$. Determinants of postoperative visual recovery in suprasellar meningiomas. Acta Neurochir (Wien) 2010;152(1):69-77

33 Ganna A, Dehdashti AR, Karabatsou K, Gentili F. Fronto-basal interhemispheric approach for tuberculum sellae meningiomas; long-term visual outcome. Br J Neurosurg 2009;23(4):422-430

34 Kitano M, Taneda M, Nakao Y. Postoperative improvement in visual function in patients with tuberculum sellae meningiomas: results of the extended transsphenoidal and transcranial approaches. J Neurosurg 2007;107(2):337-346

35 Li-Hua C, Ling C, Li-Xu L. Microsurgical management of tuberculum sellae meningiomas by the frontolateral approach: surgical technique and visual outcome. Clin Neurol Neurosurg 2011;113(1): $39-47$
36 Nakamura M, Roser F, Struck M, Vorkapic P, Samii M. Tuberculum sellae meningiomas: clinical outcome considering different surgical approaches. Neurosurgery 2006;59(5):1019-1028, discussion 1028-1029

37 Nozaki K, Kikuta K, Takagi Y, Mineharu Y, Takahashi JA, Hashimoto $\mathrm{N}$. Effect of early optic canal unroofing on the outcome of visual functions in surgery for meningiomas of the tuberculum sellae and planum sphenoidale. Neurosurgery 2008;62(4):839-844, discussion 844-846

38 Paiva-Neto MA, Tella OI Jr. Supra-orbital keyhole removal of anterior fossa and parasellar meningiomas. Arq Neuropsiquiatr 2010;68(3):418-423

39 Park CK, Jung HW, Yang SY, Seol HJ, Paek SH, Kim DG. Surgically treated tuberculum sellae and diaphragm sellae meningiomas: the importance of short-term visual outcome. Neurosurgery 2006;59 (2):238-243, discussion 238-243

40 Terasaka S, Asaoka K, Kobayashi H, Yamaguchi S. Anterior interhemispheric approach for tuberculum sellae meningioma. Neurosurgery 2011;68(1, Suppl Operative):84-88, discussion 88-89

41 Wang CW, Li YY, Zhu SG, et al. Surgical management and evaluation of prognostic factors influencing postoperative visual outcome of suprasellar meningiomas. World Neurosurg 2011; 75(2):294-302

42 Zevgaridis D, Medele RJ, Müller A, Hischa AC, Steiger HJ. Meningiomas of the sellar region presenting with visual impairment: impact of various prognostic factors on surgical outcome in 62 patients. Acta Neurochir (Wien) 2001;143(5):471-476

43 Kaptain GJ, Vincent DA, Sheehan JP, Laws ER Jr. Transsphenoidal approaches for the extracapsular resection of midline suprasellar and anterior cranial base lesions. Neurosurgery 2001;49(1): 94-100, discussion 100-101

$44 \mathrm{Chi} \mathrm{JH}, \mathrm{McDermott}$ MW. Tuberculum sellae meningiomas. Neurosurg Focus 2003;14(6):e6

45 Benjamin V, Russell SM. The microsurgical nuances of resecting tuberculum sellae meningiomas. Neurosurgery 2005;56(2, Suppl):411-417, discussion 411-417

46 Hadad G, Bassagasteguy L, Carrau RL, et al. A novel reconstructive technique after endoscopic expanded endonasal approaches: vascular pedicle nasoseptal flap. Laryngoscope 2006;116 (10):1882-1886

47 Kassam AB, Thomas A, Carrau RL, et al. Endoscopic reconstruction of the cranial base using a pedicled nasoseptal flap. Neurosurgery 2008;63(1, Suppl 1):ONS44-ONS52, discussion ONS52-ONS53 